Special Issue of the 7th International Advances in Applied Physics and Materials Science (APMAS 2017)

\title{
Optimization of Electrophoretic Deposition of YSZ
}

\author{
K.O. OSKAY ${ }^{a, *}$ AND B. DEMIREL ${ }^{b}$ \\ ${ }^{a}$ Department of Metallurgical \& Materials Engineering, Cumhuriyet University, 58140 Sivas, Turkey \\ ${ }^{b}$ Department of Materials Science \& Engineering, Erciyes University, 38280 Kayseri, Turkey
}

\begin{abstract}
Electrophoretic deposition has acquired increasing interest for its outstanding potential to produce thick ceramic coatings on complex-shaped substrates. This makes electrophoretic deposition a promising technique to obtain ceramic coatings for several applications such as solid oxide fuel cells, thermal barrier coatings and biomaterials. Response surface methodology was used to model and optimize the electrophoretic deposition process. Three mathematical models were derived to understand the kinetics of electrophoretic deposition. The optimization results showed that applied voltage had significant effects on the packing density of YSZ particles.
\end{abstract}

DOI: 10.12693/APhysPolA.134.182

PACS/topics: electrophoretic deposition, YSZ, CCD, mathematical modelling

\section{Introduction}

Ceramic coatings are widely used for protection against wear, oxidation and corrosion. The frequently used ceramic coating is yttria stabilized zirconia (YSZ) due to its excellent mechanical properties such as high bending strength and fracture toughness [1].

Plasma spray [2] and EB-PVD [3] techniques are applied to produce YSZ coatings. On the other hand electrophoretic deposition (EPD) has received attention due to its high versatility for application of different materials, simplicity in setup, low equipment cost, little restriction of the shape of substrate and capability to form complex shapes and patterns at low temperatures $[4,5]$.

The EPD process consists of two stages. In the first stage the charged powder particles, dispersed or suspended in an aqueous or non-aqueous medium are attracted and deposited onto a conductive substrate of opposite charge on application of a DC electric field [6]. After application of the coating, a suitable heat treatment might also be necessary to increase the density of deposits and to reduce the porosity of the EPD coatings after the process [7]. Recent research trends and specific application fields of EPD coatings include $\mathrm{TiO}_{2}$ for solar cells [8], hydroxyapatite for biomaterials [9], YSZ for solid oxide fuel cells [10] and YSZ for thermal barrier coatings [11].

To the best of our knowledge no published work is available on EPD kinetics of YSZ with central composite design (CCD) technique. In most of the experimental studies, the effects of parameters are investigated using conventional methods. When using conventional methods to optimize the process, one parameter is changed while others are kept at a constant level. This should be repeated for all influencing parameters, resulting in a great number of experiments. In addition to this, the major disadvantage is that it does not include the inter-

\footnotetext{
*corresponding author; e-mail: kursadoskay@gmail.com
}

active effects among the studied factors. To overcome this problem, the kinetic study of EPD process has been carried out by using the CCD technique.

This study is aimed to make EPD process commercially more viable by understanding the kinetics of the process. In accordance with this purpose, the deposited mass, packing density, thickness of the coating were selected as the responses. The particle loading, time and applied voltage were selected as the factors that affects the responses.

\section{Materials and equipment}

The YSZ powder used in this study was commercial grade $8 \mathrm{~mol} \mathrm{Y}_{2} \mathrm{O}_{3}$ stabilized zirconia (Dynano) with average particle size of about $40 \mathrm{~nm}$. The ACAC (Merck) was used as solvent. $0.2 \mathrm{~g} / \mathrm{l}$ iodine (Merck) was added to adjust particle surface charge in suspensions. Inconel 718 with diameter of $200 \mathrm{~mm}$ was used as cathode and 316L stainless steel was used as anode. Consort EV3610 power supply was used to apply potential for EPD experiments. A potential of either 30,65 and $100 \mathrm{~V}$ was applied for 60 , 90 and 120 sec. The thickness of the coatings was measured by Mitutoyo micrometer. Surface roughness value was measured using TMR200 surface roughness gauge.

In this study, CCD, which is a widely used form of RSM, was employed for optimization of the electrophoretic deposition of YSZ. In order to evaluate the influence of operating parameters on the deposited mass, the packing density and the thickness of the coating, three main factors were chosen, which were the particle loading, time and applied voltage. The RSM design of experiment was carried out using "Design expert" trial software for the analysis and testing parts of this study.

Packing density of the YSZ coating $\rho_{\text {pd }}$ was calculated using the equation below [12]:

$$
\rho_{\mathrm{pd}}=\frac{\frac{m_{\mathrm{w}}}{\rho_{\mathrm{YSZ}}}}{\frac{m_{\mathrm{w}}-m_{\mathrm{d}}}{\rho_{\mathrm{ACAC}}}+\frac{m_{\mathrm{d}}}{\rho_{\mathrm{YSZ}}}},
$$

where $m_{\mathrm{w}}$ and $m_{\mathrm{d}}$ are masses of wet and dry coating, respectively and $\rho_{\mathrm{YSZ}}$ and $\rho_{\mathrm{ACAC}}$ are the theoretical density of fully dense YSZ $\left(6.05 \mathrm{~g} / \mathrm{cm}^{3}\right)$ and pure 
acetyl acetone $\left(0.98 \mathrm{~g} / \mathrm{cm}^{3}\right)$, respectively. The thickness of the coating was measured by a thickness gauge. Statistical calculations were done according to our previous study [13]. The design matrix comprising 13 experimental runs was constructed. The regression analysis was performed to estimate the response function.

\section{Results and discussion}

Table I shows the results of CCRD experiments for studying the effect of factors along with the predicted and observed responses. The predicted and observed results in Table I prove the significance of the model.

Design of the experiments, observed and predicted results

TABLE I

\begin{tabular}{l|c|c|c|c|c|c|c|c|c}
\hline \hline & \multicolumn{3}{|c|}{ Actual values of variables } & \multicolumn{3}{c|}{ Observed } & \multicolumn{3}{c}{ Predicted } \\
\hline No. & $\begin{array}{c}\mathrm{X}_{1} \text { Particle } \\
\text { loading [g/l] }\end{array}$ & $\begin{array}{c}\mathrm{X}_{2} \text { Applied } \\
\text { voltage }[\mathrm{V}]\end{array}$ & $\begin{array}{c}\mathrm{X}_{3} \text { Deposition } \\
\text { time }[\mathrm{s}]\end{array}$ & $\mathrm{R}_{\mathrm{m}}[\mathrm{mg}]$ & $\mathrm{R}_{\mathrm{p}}[\%]$ & $\mathrm{R}_{\mathrm{t}}[\mu \mathrm{m}]$ & $\mathrm{R}_{\mathrm{m}}[\mathrm{mg}]$ & $\mathrm{R}_{\mathrm{p}}[\%]$ & $\mathrm{R}_{\mathrm{t}}[\mu \mathrm{m}]$ \\
\hline E1 & 50 & 100 & 60 & 398 & 25 & 253 & 399.90 & 25.08 & 252.17 \\
E2 & 30 & 65 & 90 & 121 & 49 & 98 & 121.95 & 46.86 & 95.74 \\
E3 & 10 & 100 & 120 & 175 & 22 & 120 & 176.90 & 22.08 & 119.17 \\
E4 & 30 & 65 & 90 & 120 & 47 & 95 & 121.95 & 46.86 & 95.74 \\
E5 & 10 & 65 & 90 & 50 & 38 & 46 & 49.54 & 41.36 & 42.74 \\
E6 & 50 & 65 & 90 & 275 & 49 & 152 & 274.54 & 52.36 & 148.74 \\
E7 & 30 & 30 & 90 & 62 & 48 & 32 & 64.87 & 47.83 & 33.67 \\
E8 & 30 & 100 & 90 & 284 & 27 & 204 & 280.21 & 26.83 & 205.67 \\
E9 & 30 & 65 & 60 & 43 & 47 & 68 & 42.54 & 45.36 & 72.24 \\
E10 & 30 & 65 & 120 & 138 & 50 & 115 & 137.54 & 48.36 & 119.24 \\
E11 & 30 & 65 & 90 & 123 & 48 & 96.2 & 121.95 & 46.86 & 95.74 \\
E12 & 10 & 30 & 60 & 33 & 53 & 39 & 31.56 & 53.08 & 38.17 \\
E13 & 50 & 30 & 120 & 116 & 49 & 70 & 114.56 & 49.08 & 69.17
\end{tabular}

According to designed experimental data, the models for the deposit mass, Eq. (2), the packing density, Eq. (3), and the thickness, Eq. (4), of the coating were obtained as:

$$
\begin{aligned}
& \left(R_{\mathrm{m}}\right) \text { deposit mass }[\mathrm{mg}]= \\
& \quad 18.70034-8.04990 X_{1}-8.91446 X_{2}+5.73584 X_{3} \\
& \quad+0.11786 X_{1} X_{2}+0.034286 X_{2} X_{3} \\
& \quad+0.10024 X_{1}^{2}+0.04132 X_{2}^{2} \\
& \quad-0.035450 X_{3}^{2}
\end{aligned}
$$

$\left(R_{\mathrm{p}}\right)$ packing density $[\%]=$

$$
\begin{aligned}
& 76.47400-0.51429 X_{1}+0.078547 X_{2}-0.46845 X_{3} \\
& +0.00464286 X_{1} X_{2}+0.00541667 X_{1} X_{3} \\
& +0.00547619 X_{2} X_{3}-0.00777454 X_{2}^{2}
\end{aligned}
$$

$\left(R_{\mathrm{t}}\right)$ thickness $[\mu \mathrm{m}]=$

$$
\begin{aligned}
& 161.89845-4.9 X_{1}-3.21028 X_{2}-0.95952 X_{3} \\
& +0.07 X_{1} X_{2}+0.033333 X_{1} X_{3} \\
& +0.011429 X_{2} X_{3}+0.019530 X_{2}^{2} .
\end{aligned}
$$

Anova table of the $R_{\mathrm{m}}$ response

TABLE II

\begin{tabular}{l|c|c|c}
\hline \hline Factor & S.S. & $f$-value & $p$-value \\
\hline model & 143288.69 & 1752.43 & $<0.0001$ \\
residual & 40.60 & & \\
lack of fit & 35.94 & 7.20 & 0.1149 \\
pure error & 4.67 & & \\
cor. total & 143305.69 & & \\
\hline \hline $\mathrm{R}^{2}$ & 0.9997 & pred $\mathrm{R}^{2}$ & 0.9907 \\
adj. $\mathrm{R}^{2}$ & 0.9991 & adeq. pr. & 138.944
\end{tabular}

Anova table of the $R_{\mathrm{p}}$ response

TABLE III

\begin{tabular}{l|c|c|c}
\hline \hline Factor & S.S. & $f$-value & $p$-value \\
\hline model & 1347.29 & 28.35 & 0.0010 \\
residual & 33.94 & & \\
lack of fit & 31.94 & 10.64 & 0.0871 \\
pure error & 2.00 & & \\
cor. total & 1381.23 & & \\
\hline \hline $\mathrm{R}^{2}$ & 0.9754 & pred $\mathrm{R}^{2}$ & 0.8323 \\
adj. $\mathrm{R}^{2}$ & 0.9410 & adeq. pr. & 15.168
\end{tabular}

probability of $0.0001,0.0010$ and 0.0001 . If the $p$-value is smaller than 0.05 , the model is significant. The results indicated that the models used to fit the response variable were significant and adequate to represent the relationship between the response and the factors [14]. The lack of fit p-value $R_{\mathrm{m}}, R_{\mathrm{p}}$ and $R_{\mathrm{t}}$ are $0.114,0.087$ and 0.094 , respectively, which imply that the lack of fits values are insignificant. The corresponding variables would be more significant if the absolute $f$-value would become greater and the p-value would become smaller. 
Anova table of the $R_{\mathrm{t}}$ response

TABLE IV

\begin{tabular}{l|c|c|c}
\hline \hline Factor & S.S. & $f$-value & $p$-value \\
\hline model & 50112.62 & 501.25 & $<0.0001$ \\
residual & 71.41 & & \\
lack of fit & 66.85 & 9.77 & 0.0942 \\
pure error & 4.56 & & \\
cor. total & 50184.03 & & \\
\hline \hline $\mathrm{R}^{2}$ & 09986 & pred $\mathrm{R}^{2}$ & 0.9819 \\
adj. $\mathrm{R}^{2}$ & 0.9966 & adeq. pr. & 73.702
\end{tabular}

The high value of $R_{\text {adj }}^{2}$ indicates that the equation is capable of representing the system under the given experimental domain [15]. The value of adjusted determination coefficient $R_{\text {adj }}^{2}$ was found to be $0.9991,0.9410$, and 0.9986 for, $R_{\mathrm{m}}, R_{\mathrm{p}}$ and $R_{\mathrm{t}}$, respectively. This means that the calculated model was able to explain $99.99 \%$, $94.10 \%$ and $99.86 \%$ of the total variations in the system.

The "adequate precision" parameter measures the signal to noise ratio. A ratio greater than 4 is desirable. Our ratios were found to be $138.944,15.168$ and 73.702 for $R_{\mathrm{m}}, R_{\mathrm{p}}$ and $R_{\mathrm{t}}$, respectively. These models are sensitive at the boundary values and can be used to navigate the design space. All of these results show that the constructed models made for understanding the kinetics of the EPD coating process are significant.

Figures $1 \mathrm{a}$ and $\mathrm{b}$ illustrate the effect of two factors on the deposited mass. Figure 1a shows that $R_{\mathrm{m}}$ increases with the increase of particle loading and applied voltage. At low YSZ concentration, with the increment of applied voltage $R_{\mathrm{m}}$ increases slowly; however, $R_{\mathrm{m}}$ increases extremely with the increase of the YSZ concentration (particle loading).
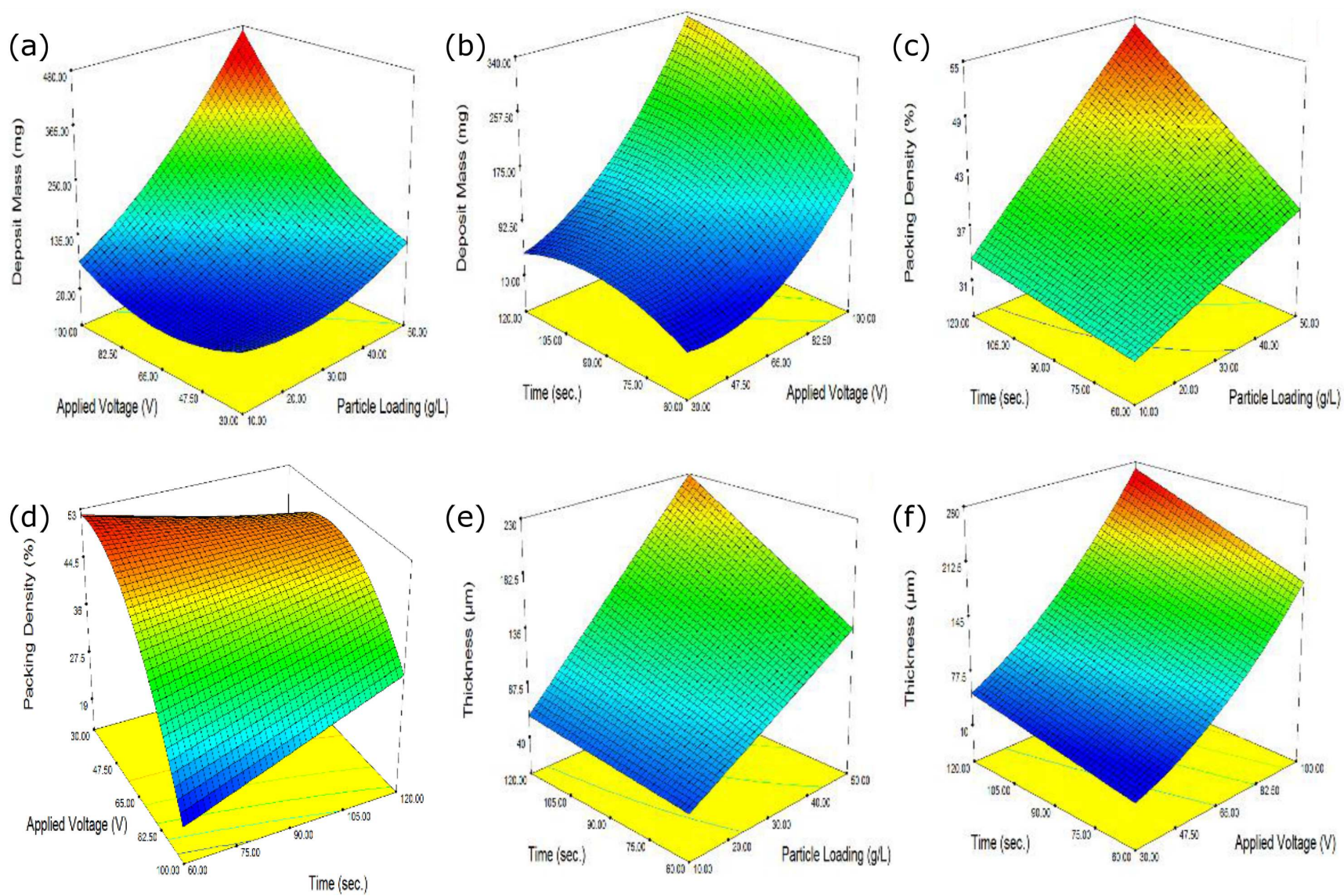

Fig. 1. Response surface plots showing the effect of two factors on EPD process: (a) deposit mass vs applied voltage and particle loading, (b) deposit mass vs time and applied voltage, (c) packing density vs particle loading and time, (d) packing density vs applied voltage and time, (e) coating thickness vs time and particle loading, (f) coating thickness vs time and applied voltage.

The similar results have been obtained in Fig. 1e and $\mathrm{f}$. As shown in Fig. 1e, the coating thickness increased linearly with the increase of applied voltage and particle loading. From the surface plots it is apparent that the effect of time becomes more significant with the increase of the applied voltage and particle loading. Therefore, it is desirable to choose higher concentration of YSZ and higher applied voltage to increase the coating thickness.

Figure 1c shows the combined effect of two factors on the packing density. It can be observed that the packing density of the coating increases with the increase of the particle loading and time. However, it is seen from 
Fig. 1d that the decrease of applied voltage resulted in increase of the packing density. In addition, $R_{\mathrm{p}}$ reaches a peak value at approximately $48 \mathrm{~V}$. It may be referred to the higher voltage that causes the particles to move too quickly within a time in which the particles cannot find enough time to settle in their best positions in order to form a close-packed structure [16].

In order to optimize the EPD process, Eqs. (2)-(4) were used. Quadratic programming software package was employed to maximize $R_{\mathrm{t}}$ and $R_{\mathrm{p}}$ and to minimize the particle loading. The optimum levels of factors were found to be particle loading of $33 \mathrm{~g} / \mathrm{l}$, applied voltage of $48 \mathrm{~V}$, and time of $120 \mathrm{~s}$ for deposit mass of $102 \mathrm{mg}$, packing density of $49.50 \%$, and thickness of $84.66 \mu \mathrm{m}$.

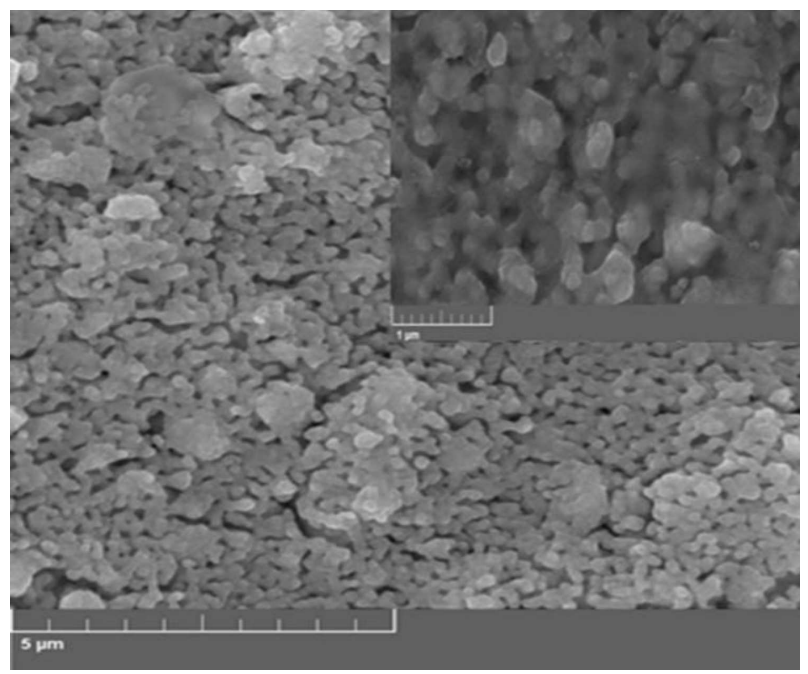

Fig. 2. SEM image of the sintered coating.

YSZ coatings were produced under optimum parameters and sintered at $1150{ }^{\circ} \mathrm{C}$ for two hours. Based on the surface roughness measurements, the $R_{\mathrm{a}}$ value was $2.9 \mu \mathrm{m}$. Figure 2 shows the SEM image of the sintered YSZ coating. The surface microstructure of the sintered coating consists of large crystallites surrounded by small particles. High magnitude microstructure image shows that grains were well developed in the porous microstructure.

\section{Conclusions}

The present study was aimed to explore the effects of various coating parameters on EPD kinetics. For this purpose three mathematical models were obtained with the design of experiments. The most influential factor for packing density was the applied voltage. The $R_{\mathrm{p}}$ model verifies that increasing voltage decreases the packing density. On the other hand, the thickness and the deposited mass increase with the increasing voltage. This study demonstrates that CCD can be used for analysis of the EPD process.

\section{Acknowledgments}

This work was supported by Research Fund of the Erciyes University (FDA-2016-6752).

\section{References}

[1] B. Baufeld, O. van der Biest, H.-J. Rätzer-Scheibe, J. Eur. Ceram. Soc. 28, 1793 (2008).

[2] P.C. Tsai, C.F. Tseng, C.W. Yang, I.C. Kuo, Y.L. Chou, J.W. Lee, Surf. Coatings Technol. 228 , S11 (2013).

[3] P. Mechnich, W. Braue, U. Schulz, J. Am. Ceram. Soc. 94, 925 (2011).

[4] M. Hekmatfar, S. Moshayedi, S.A. Ghaffari, H.R. Rezaei, F. Golestani-Fard, Mater. Lett. 65, 3421 (2011).

[5] J. Ma, C. Wang, K.W. Peng, Biomaterials 24, 3505 (2003).

[6] L. Besra, M. Liu, Prog. Mater. Sci. 52, 1 (2007).

[7] A. Shahriari, H. Aghajani, J. Mater. Eng. Perform. 25, 4369 (2016).

[8] S. Dor, S. Rühle, A. Ofir, M. Adler, L. Grinis, A. Zaban, Colloids Surf. A Physicochem. Eng. Asp. 342, 70 (2009).

[9] M. Farrokhi-Rad, S.K. Loghmani, T. Shahrabi, S. Khanmohammadi, J. Eur. Ceram. Soc. 34, 97 (2014).

[10] L. Jia, Z. Lü, X. Huang, Z. Liu, K. Chen, X. Sha, G. Li, W. Su, J. Alloys Compd. 424, 299 (2006).

[11] H. Maleki-Ghaleh, M. Rekabeslami, M.S. Shakeri, M.H. Siadati, M. Javidi, S.H. Talebian, H. Aghajani, Appl. Surf. Sci. 280, 666 (2013).

[12] C. Ji, I.P. Shapiro, P. Xiao, J. Eur. Ceram. Soc. 29, 3167 (2009).

[13] K.O. Oskay, M. Kul, Water Sci. Technol. 72, 52 (2015).

[14] M. Kul, K.O. Oskay, M. Simsir, H. Subutay, H. Kirgezen, Trans. Nonferrous Met. Soc. China 25, 2753 (2015)

[15] O. Celep, N. Aslan, İ. Alp, G. Taşdemir, Powder Technol. 208, 121 (2011).

[16] J. H. Dickerson, A.R. Boccacini Electrophoretic Deposition of Nanometerials, Springer, New York 2012, p.48. 